\title{
Nutrition and Vulnerable Groups
}

\author{
Amanda Devine ${ }^{1, *(1)}$ and Tanya Lawlis ${ }^{2}$ \\ 1 School of Medical and Health Sciences, Edith Cowan University, Joondalup, Perth WA 6027, Australia \\ 2 Discipline Nutrition and Dietetics, University of Canberra, Canberra, ACT 2601, Australia; \\ Tanya.Lawlis@canberra.edu.au \\ * Correspondence: a.devine@ecu.edu.au; Tel.: +61-8-6304-5527
}

Received: 9 May 2019; Accepted: 13 May 2019; Published: 14 May 2019

Food insecurity is a complex 'wicked' problem that results from a range of unstable and uncertain physical, social, cultural, and economic factors that limit access to nutritious food. Globally, 800 million people are undernourished, around 1.9 billion are overweight/obese, and 2 billion have micronutrient deficiency [1]. This, in part, is explained by changes in food production and manufacturing and their impacts on climate change [2], the retraction in economic climates, increases in food prices, and, in some regions, reduced food availability and access [3,4]. Vulnerable groups include, but are not limited to, migrant populations, Indigenous peoples, elderly populations, pregnant women, those with disabilities, homelessness people, young children, and youth. Poor nutrition during significant periods of growth and development and throughout life impacts long-term health outcomes; increases non-communicable disease prevalence, healthcare costs, and disease burden; and negatively impacts economic and human productivity [5]. This special edition has brought together a variety of articles, some positioned in developing countries where disease burden is high and food insecurity issues impact the growth and development of young children while also negatively affecting adults, specifically their mental and physical health. This issue, Nutrition and Vulnerable Groups, reports novel strategies to address individual, household, and community food security, and draws together quantitative and qualitative research that has attempted to address the challenges of food security while considering the complexity of the problem, the need for locally-driven and scalable solutions, and policy implications.

The double burden of disease exists in many countries, especially in developing countries and those transitioning to Western-style diets. Factors influencing infant feeding practices in Haitian children have been examined, and despite a high prevalence of malnutrition and poor adherence to the World Health Organization's recommendations exacerbating malnutrition, factors including low maternal education and greater family size have been negatively associated with infant nutritional status [6]. Households that experience child stunting have simultaneous issues with overweight and obese parents, the odds of which relate to the level of food insecurity and appear to be greater in those with mild food insecurity [7]. This may be explained by marginally greater access to food, but food of poor nutritional quality, explaining the juxtaposition of the disease burden. Other vulnerable food insecure groups, such as refugees, are experiencing additional impacts of increased obesity including metabolic syndrome. An increased likelihood of this condition has been related to older age, synonymous to years of exposure, as well as younger marital age [8]. Author recommendations suggest large-scale community intervention programs to tackle obesity as well as cultural change to increase age at marriage.

In both developing and developed countries, socioeconomic status is a known driver of food insecurity and the association with increased Body Mass Index (BMI) in children and adults is clear. This issue examines children who have experienced abandonment and are being supported by the welfare state, and how sociodemographic factors negatively impact children's body size and body shape satisfaction [9]. Authors recommend body image awareness as a consideration in obesity prevention programs. Moreover, poor academic performance in low socioeconomic adolescents has 
been related to greater body size and fatness, alone or in combination with diet and exercise patterns, and seems more likely to occur in males than females [10]. Poor food choice or limited access to nourishing food, such as fruit and vegetables, is associated with food insecure populations [11,12], especially youth, and is explained by a lack of economic means, education, food availability, access, and other socioeconomic factors. Support mechanisms, including programs to increase access to healthy food, are paramount for vulnerable communities, and this issue provides evidence of the importance of food pantries [13], as well as school and university settings [14,15]. However, in some countries popular restaurants that support low income families and provide cheap, energy-dense foods to support the cultural aspects of the traditional food supply simultaneously increase the risk of chronic disease [16].

Similarly to developing countries, cities and neighborhoods in developed countries are experiencing a greater emergence of vulnerable populations, thus requiring an informed workforce to support these communities. This workforce needs to identify modifiable factors that can be incorporated into future schemes and food security interventions in order to efficiently manage food shortages and address drivers in the immediate and broader geographical locations [17,18]. A greater understanding from the workforce is required, as evidence suggests a divergence in views between those who address the problem and those with the lived experience of food insecurity [19]. Therefore, more engagement and attention to those with the lived experience is required to inform interventions. Strategies outlined in this issue to influence nutritional intake include greater access to local food pantries [13], educational interventions for children and adults [20,21], and increased local food production and livestock keeping [22].

Food literacy is among the key components required to improve food security, as evidence in this issue highlights the lack of understanding by food-insecure households about food labelling, product attributes, and food choice [12]. Authors in this issue outline a framework that builds the capacity and capability of the charitable food organization workforce, through the inclusion of the university or higher education sector, to support their training needs in food literacy [15].

To better understand the practice and policy environment of the broader food system, barriers and enablers have been examined [17]. This issue has outlined novel applications of a Systemic Innovation Lab, which capture initiatives within a defined local geographical area that support community food security [18]. This innovative system examines systems change. Initiatives that had a greater number of characteristics to reinforce a better way of working to address food insecurity or had strategies and systems to implement place-based change were identified. Those without these characteristics were identified, and strategies were co-designed by the community to improve the initiative to more comprehensively address food security. Community and government buy-in, relationship building, and education were among the strategies required to improve systems change.

The diverse articles in this special issue highlight the complexity and extent to which nutrition-related issues may impact vulnerable and marginalized groups. The impact of over- and undernutrition is not specific to one group or area, as similar problems have been identified in developing and developed countries and between rural and urban areas. As seen by the various findings and recommendations, not only is more work in this area required but the translation of this work to practice and policy is imperative if we are to address the issues impacting upon the nutrition and health of those experiencing vulnerability.

Author Contributions: A.D. and T.L. wrote the editorial.

Funding: This research received no external funding.

Conflicts of Interest: The authors declare no conflict of interest.

\section{References}

1. Global Panel on Agriculture and Food Systems for Nutrition. Food Systems and Diets: Facing the Challenges of the 21st Century; Global Panel on Agriculture and Food Systems for Nutrition: London, UK, 2016. 
2. Willett, W.; Rockstrom, J.; Loken, B.; Springmann, M.; Lang, T.; Vermeulen, S.; Garnett, T.; Tilman, D.; DeClerck, F.; Wood, A.; et al. Food in the Anthropocene: The EAT-Lancet Commission on healthy diets from sustainable food systems. Lancet 2019, 393, 447-492. [CrossRef]

3. Springmann, M.; Clark, M.; Mason-D'Croz, D.; Wiebe, K.; Bodirsky, B.L.; Lassaletta, L.; de Vries, W.; Vermeulen, S.J.; Herrero, M.; Carlson, K.M.; et al. Options for keeping the food system within environmental limits. Nature 2018, 562, 519-525. [CrossRef] [PubMed]

4. Global Panel. Improving Nutrition through Enhanced Food Environments; Global Panel on Agriculture and Food Systems for Nutrition: London, UK, 2017.

5. GBD Diet Collaborators. Health effects of dietary risks in 195 countries, 1990-2017: A systematic analysis for the Global Burden of Disease Study 2017. Lancet 2019, 393, 1916-1918. [CrossRef]

6. Irarrazaval, B.; Barja, S.; Bustos, E.; Doirsaint, R.; Senethmm, G.; Guzman, M.P.; Uauy, R. Influence of Feeding Practices on Malnutrition in Haitian Infants and Young Children. Nutrients 2018, 10. [CrossRef] [PubMed]

7. Mahmudiono, T.; Nindya, T.S.; Andrias, D.R.; Megatsari, H.; Rosenkranz, R.R. Household Food Insecurity as a Predictor of Stunted Children and Overweight/Obese Mothers (SCOWT) in Urban Indonesia. Nutrients 2018, 10. [CrossRef] [PubMed]

8. Massad, S.G.; Khalili, M.; Karmally, W.; Abdalla, M.; Khammash, U.; Mehari, G.M.; Deckelbaum, R.J. Metabolic Syndrome among Refugee Women from the West Bank, Palestine: A Cross-Sectional Study. Nutrients 2018, 10. [CrossRef] [PubMed]

9. Rahim, N.N.; Chin, Y.S.; Sulaiman, N. Socio-Demographic Factors and Body Image Perception Are Associated with BMI-For-Age among Children Living in Welfare Homes in Selangor, Malaysia. Nutrients 2019, 11. [CrossRef] [PubMed]

10. Correa-Burrows, P.; Rodriguez, Y.; Blanco, E.; Gahagan, S.; Burrows, R. Increased Adiposity as a Potential Risk Factor for Lower Academic Performance: A Cross-Sectional Study in Chilean Adolescents from Low-to-Middle Socioeconomic Background. Nutrients 2018, 10. [CrossRef] [PubMed]

11. Godrich, S.L.; Loewen, O.K.; Blanchet, R.; Willows, N.; Veugelers, P. Canadian Children from Food Insecure Households Experience Low Self-Esteem and Self-Efficacy for Healthy Lifestyle Choices. Nutrients 2019, 11. [CrossRef] [PubMed]

12. Butcher, L.M.; Ryan, M.M.; O'Sullivan, T.A.; Lo, J.; Devine, A. Food-Insecure Household's Self-Reported Perceptions of Food Labels, Product Attributes and Consumption Behaviours. Nutrients 2019, 11. [CrossRef] [PubMed]

13. Wright, B.N.; Bailey, R.L.; Craig, B.A.; Mattes, R.D.; McCormack, L.; Stluka, S.; Franzen-Castle, L.; Henne, B.; Mehrle, D.; Remley, D.; et al. Daily Dietary Intake Patterns Improve after Visiting a Food Pantry among Food-Insecure Rural Midwestern Adults. Nutrients 2018, 10. [CrossRef] [PubMed]

14. Godrich, S.L.; Davies, C.R.; Darby, J.; Devine, A. Strategies to Address the Complex Challenge of Improving Regional and Remote Children's Fruit and Vegetable Consumption. Nutrients 2018, 10. [CrossRef] [PubMed]

15. Lawlis, T.; Sambell, R.; Douglas-Watson, A.; Belton, S.; Devine, A. The Food Literacy Action Logic Model: A Tertiary Education Sector Innovative Strategy to Support the Charitable Food Sectors Need for Food Literacy Training. Nutrients 2019, 11. [CrossRef] [PubMed]

16. Carrijo, A.P.; Botelho, R.B.A.; Akutsu, R.; Zandonadi, R.P. Is What Low-Income Brazilians Are Eating in Popular Restaurants Contributing to Promote Their Health? Nutrients 2018, 10. [CrossRef]

17. Haynes-Maslow, L.; Osborne, I.; Jilcott Pitts, S.B. Best Practices and Innovative Solutions to Overcome Barriers to Delivering Policy, Systems and Environmental Changes in Rural Communities. Nutrients 2018, 10. [CrossRef] [PubMed]

18. Godrich, S.L.; Payet, J.; Brealey, D.; Edmunds, M.; Stoneham, M.; Devine, A. South West Food Community: A Place-Based Pilot Study to Understand the Food Security System. Nutrients 2019, 11. [CrossRef] [PubMed]

19. Butcher, L.M.; Ryan, M.M.; O'Sullivan, T.A.; Lo, J.; Devine, A. What Drives Food Insecurity in Western Australia? How the Perceptions of People at Risk Differ to Those of Stakeholders. Nutrients 2018, 10. [CrossRef] [PubMed]

20. El Harake, M.D.; Kharroubi, S.; Hamadeh, S.K.; Jomaa, L. Impact of a Pilot School-Based Nutrition Intervention on Dietary Knowledge, Attitudes, Behavior and Nutritional Status of Syrian Refugee Children in the Bekaa, Lebanon. Nutrients 2018, 10. [CrossRef] [PubMed] 
21. Law, L.S.; Norhasmah, S.; Gan, W.Y.; Siti NurAsyura, A.; Mohd Nasir, M.T. The Identification of the Factors Related to Household Food Insecurity among Indigenous People (Orang Asli) in Peninsular Malaysia under Traditional Food Systems. Nutrients 2018, 10. [CrossRef] [PubMed]

22. de Bruyn, J.; Thomson, P.C.; Darnton-Hill, I.; Bagnol, B.; Maulaga, W.; Alders, R.G. Does Village Chicken-Keeping Contribute to Young Children's Diets and Growth? A Longitudinal Observational Study in Rural Tanzania. Nutrients 2018, 10. [CrossRef] [PubMed]

(C) 2019 by the authors. Licensee MDPI, Basel, Switzerland. This article is an open access article distributed under the terms and conditions of the Creative Commons Attribution (CC BY) license (http://creativecommons.org/licenses/by/4.0/). 